\title{
TU/e emonownen

\section{High-performance organic integrated circuits based on solution processable polymer-small molecule blends}

\section{Citation for published version (APA):}

Smith, J., Hamilton, R., Heeney, M., Leeuw, de, D. M., Cantatore, E., Anthony, J. E., McCulloch, I., Bradley, D. D. C., \& Athopoulos, T. D. (2008). High-performance organic integrated circuits based on solution processable polymer-small molecule blends. Applied Physics Letters, 93(25), 253301-1-3. [253301]. https://doi.org/10.1063/1.3050525

DOI:

$10.1063 / 1.3050525$

Document status and date:

Published: 01/01/2008

\section{Document Version:}

Publisher's PDF, also known as Version of Record (includes final page, issue and volume numbers)

\section{Please check the document version of this publication:}

- A submitted manuscript is the version of the article upon submission and before peer-review. There can be important differences between the submitted version and the official published version of record. People interested in the research are advised to contact the author for the final version of the publication, or visit the $\mathrm{DOI}$ to the publisher's website.

- The final author version and the galley proof are versions of the publication after peer review.

- The final published version features the final layout of the paper including the volume, issue and page numbers.

Link to publication

\section{General rights}

Copyright and moral rights for the publications made accessible in the public portal are retained by the authors and/or other copyright owners and it is a condition of accessing publications that users recognise and abide by the legal requirements associated with these rights.

- Users may download and print one copy of any publication from the public portal for the purpose of private study or research.

- You may not further distribute the material or use it for any profit-making activity or commercial gain

- You may freely distribute the URL identifying the publication in the public portal.

If the publication is distributed under the terms of Article 25fa of the Dutch Copyright Act, indicated by the "Taverne" license above, please follow below link for the End User Agreement:

www.tue.nl/taverne

Take down policy

If you believe that this document breaches copyright please contact us at:

openaccess@tue.nl

providing details and we will investigate your claim. 


\title{
High-performance organic integrated circuits based on solution processable polymer-small molecule blends
}

\author{
Jeremy Smith, ${ }^{1}$ Richard Hamilton, ${ }^{2}$ Martin Heeney, ${ }^{3}$ Dago M. de Leeuw, ${ }^{4}$ \\ Eugenio Cantatore, ${ }^{5}$ John E. Anthony, ${ }^{6}$ lain McCulloch, ${ }^{2}$ Donal D. C. Bradley, ${ }^{1}$ and \\ Thomas D. Anthopoulos ${ }^{1, a)}$ \\ ${ }^{1}$ Department of Physics, Blackett Laboratory, Imperial College London, London SW7 2BW, United Kingdom \\ ${ }^{2}$ Department of Chemistry, Imperial College London, London SW7 2AZ, United Kingdom \\ ${ }^{3}$ Department of Materials, Queen Mary University of London, Mile End Road, London E1 4NS, \\ United Kingdom \\ ${ }^{4}$ Philips High-Tech Campus, Professor Holstlaan 4, 5656 AA Eindhoven, The Netherlands \\ ${ }^{5}$ Department of Electrical Engineering, Eindhoven University of Technology, $5600 \mathrm{MB}$ Eindhoven, \\ The Netherlands \\ ${ }^{6}$ Department of Chemistry, University of Kentucky, Lexington, Kentucky 40506-0055, USA
}

(Received 2 October 2008; accepted 26 November 2008; published online 23 December 2008)

\begin{abstract}
The prospect of realizing high-performance organic circuits via large-area fabrication is attractive for many applications of organic microelectronics. Here we report solution processed organic field-effect transistors and circuits based on polymer-small molecule blends comprising of polytriarylamine and 5,11-bis(triethylsilylethynyl) anthradithiophene. By optimizing blend composition and deposition conditions we are able to demonstrate short channel, bottom-gate, bottom-contact transistors with high mobility and excellent reproducibility. Using these transistors we have built unipolar voltage inverters and ring oscillators with a single stage delay of 712 ns. These are among the fastest organic circuits reported to date and could satisfy the performance requirements of low-end electronic applications. (C) 2008 American Institute of Physics.
\end{abstract}

[DOI: $10.1063 / 1.3050525]$

Organic field-effect transistors (OFETs) are rapidly becoming a competitive technology for use in commercial electronics particularly where low manufacturing cost and large volume processing are important. ${ }^{1,2}$ In general organic materials are best suited to applications that do not require the high performance of, for example, crystalline silicon. However, even for low-end electronic circuits, high charge carrier mobility and good device-to-device reproducibility, depending partly on film structural uniformity, are important since several transistors must function in unison. ${ }^{3}$ Currently the best method of producing such high quality films is by vacuum thermal evaporation of the organic semiconductor. Using this technique OFETs with carrier mobilities of up to $6 \mathrm{~cm}^{2} / \mathrm{V}$ s have been demonstrated. ${ }^{4,5}$

An alternative, and possibly less complex, approach for the fabrication of organic transistors and circuits is via solution processing. ${ }^{6}$ This offers the potential for much cheaper devices that can be patterned using large-area deposition methods such as ink-jet printing. ${ }^{7}$ Film formation from solution though can be difficult to control, and there is usually a trade-off between high mobility and ease of processing. Despite this, integrated circuits based on numerous soluble organic semiconductors including polymers such as poly(3-alkylthiophene $)^{8}$ as well as small molecules ${ }^{9}$ have been reported. Very recently solution processed blends ${ }^{10-12}$ of polymeric and small molecule semiconductors have shown great promise in marrying solution processability, a typical characteristic of polymers, with high carrier mobility, a characteristic of strongly interacting $(\pi$-stacked $)$ small molecules. Based on this approach, we have recently

\footnotetext{
a) Author to whom correspondence should be addressed. Electronic mail: thomas.anthopoulos@imperial.ac.uk.
}

demonstrated solution processed top-gate, bottom-contact (TG-BC) transistors with hole mobilities greater than $2 \mathrm{~cm}^{2} / \mathrm{V} \mathrm{s}^{13}$ In these devices the fluorinated acene 5,11bis(triethylsilylethynyl) anthradithiophene $(\text { diF-TESADT })^{14,15}$ provides the efficient charge transport pathways, while the amorphous polymer, polytriarylamine (PTAA), acts as a matrix and aids uniformity and ease of processing. Although diF-TESADT in itself has been shown to have a high mobility, ${ }^{15}$ the decrease in device-to-device variation observed for blend-based transistors is advantageous especially for the fabrication of integrated circuits. It is important to note that although the polymer matrix does not contribute significantly to charge transport, there is a systematic increase in hole mobility when changing from an insulating polymer (e.g., polystyrene) to PTAA. This is possibly due to improved charge injection from the metal contact to the highest occupied molecular orbital (HOMO) energy level $(\sim 5.35 \mathrm{eV}$, as determined by cyclic voltammetry) of diFTESADT and/or increased conduction pathways between high mobility diF-TESADT crystallites within the film via PTAA.

Here we demonstrate that the same binary semiconductor blend (i.e., diF-TESADT:PTAA) can be extended for use in transistors based on simpler device structures. In particular, by carefully controlling the microstructure of the semiconductor film, we are able to realize high mobility $\left(0.1 \mathrm{~cm}^{2} / \mathrm{V} \mathrm{s}\right)$ bottom-gate, bottom-contact (BG-BC) transistors fabricated at room temperature via spin coating. By integrating a number of such BG-BC transistors we demonstrate logic inverters and multistage ring oscillators with the aim of providing a more realistic and dynamic measure of the performance of polymer-small molecule blends in real applications. 


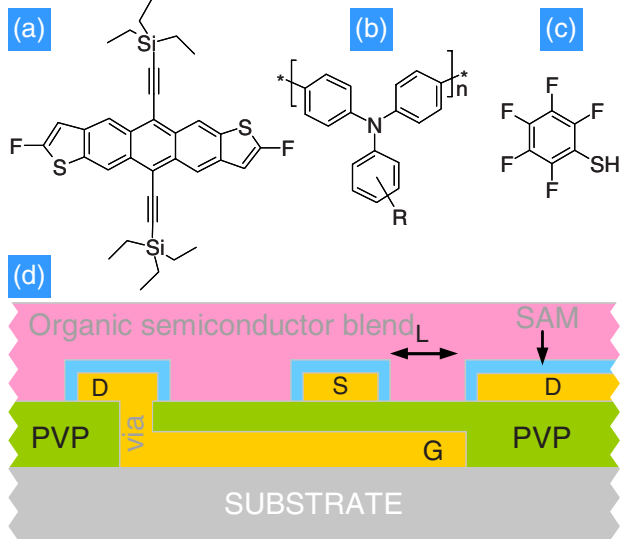

(e)

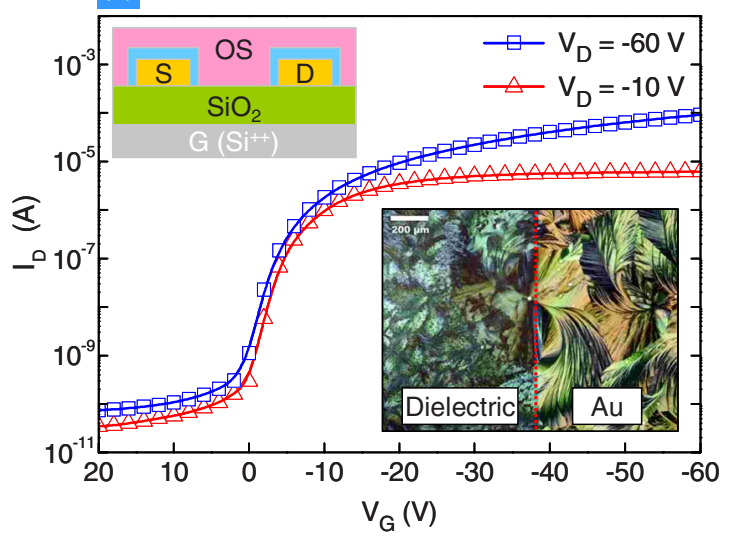

FIG. 1. (Color online) Molecular structures of (a) diF-TESADT, (b) PTAA, and (c) pentafluorobenzene thiol. (d) Generic structure of PVP based transistors employed for the construction of the invert and ring oscillator circuits. (e) Transfer characteristics of a diF-TESADT:PTAA based organic transistor employing $\mathrm{SiO}_{2}$ as the gate dielectric. Top inset in (e) shows the BG-BC device architecture employed, while the bottom inset shows the optical micrograph of a diF-TESADT:PTAA film spin cast on a substrate containing the dielectric and a patterned $\mathrm{Au}$ electrode.

The semiconductor used in these experiments consisted of a 1:1 by weight blend of diF-TESADT and PTAA [Figs. 1(a) and 1(b)]. Discrete BG-BC transistors were made using doped $p$-type $\mathrm{Si}$ wafers acting as a common gate electrode and a $200 \mathrm{~nm}$ thermally grown $\mathrm{SiO}_{2}$ layer as the dielectric. Using conventional photolithography, gold source-drain (SD) electrodes were defined with channel lengths and widths in the ranges of 1-40 $\mu \mathrm{m}$ and 1-20 mm, respectively. A $10 \mathrm{~nm}$ layer of titanium was used as an adhesion layer for the gold on $\mathrm{SiO}_{2}$. Integrated circuits and a number of discrete transistors were fabricated using polyvinylphenol (PVP) as gate dielectric employing the BG-BC device architecture [Fig. 1(d)]. The detailed fabrication process is described elsewhere. ${ }^{1}$ In brief, the circuit structure consisted of gold electrodes and interconnects and a $300 \mathrm{~nm}$ layer of PVP patterned to form vias. Source and drain electrodes were treated with the self-assembled monolayer (SAM) pentafluorobenzene thiol ${ }^{16}[$ Fig. 1(c)] prior to semiconductor deposition to improve charge injection into the HOMO of diFTESADT and film crystallization onto the SD contacts [see optical micrograph in Fig. 1(e)]. Semiconductor blend processing was carried out by spin coating, followed by annealing at $100{ }^{\circ} \mathrm{C}$ for $150 \mathrm{~s}$ in $\mathrm{N}_{2}$. For the best performance, integrated circuits were further annealed in vacuo $\left(10^{-5} \mathrm{mbar}\right)$ for $30 \mathrm{~min}$ at $100{ }^{\circ} \mathrm{C}$. The stage delay $\left(\tau_{d}\right)$ for each of the ring oscillators was calculated from the measured oscillation frequency $\left(f_{\text {osc }}\right)$ using $\tau_{d}=\left(1 / 2 n f_{\text {osc }}\right)$, where $n$ is the number of inverting stages.

The effect of the SAM on film crystallization is shown in the optical micrograph in the inset of Fig. 1(e). The deposited film forms larger crystalline domains on top of the Au electrode than on the surface of the dielectric. If the SAM functionalization step is omitted, then the morphology of the blend films is found to resemble that on the gate dielectric. These effects are discussed in detail in Refs. 13 and 16. It is to be noted that the derived mobility in discrete BG-BC transistors seems unaffected by the use of the SAM; however, there was a slight increase in $f_{\text {osc }}$ when the SAM is employed possibly due to a reduction in the device parameter spread.

We first fabricated $\mathrm{BG}-\mathrm{BC}$ transistors employing $\mathrm{SiO}_{2}$ as the gate dielectric [top inset in Fig. 1(e)]. Good operating characteristics [Fig. 1(e)] with hole mobilities of up to $0.1 \mathrm{~cm}^{2} / \mathrm{V}$ s were obtained. Switching to a PVP dielectric produced transistors with comparable maximum carrier mobilities; however, the operating characteristics of these devices exhibited increased hysteresis and lower current on/off ratios. Despite this drawback we find that it is still possible to use PVP based transistors for the fabrication of inverters and ring oscillators. We note that no functional circuits could be obtained when pristine films of diF-TESADT were employed. We attribute this to the highly anisotropic crystalline nature of the neat diF-TESADT films and therefore to a possible increase in device-to-device parameter variation. In this respect, the narrowing of device-to-device parameter (i.e., mobility, threshold voltage, etc.) spread observed in blend-

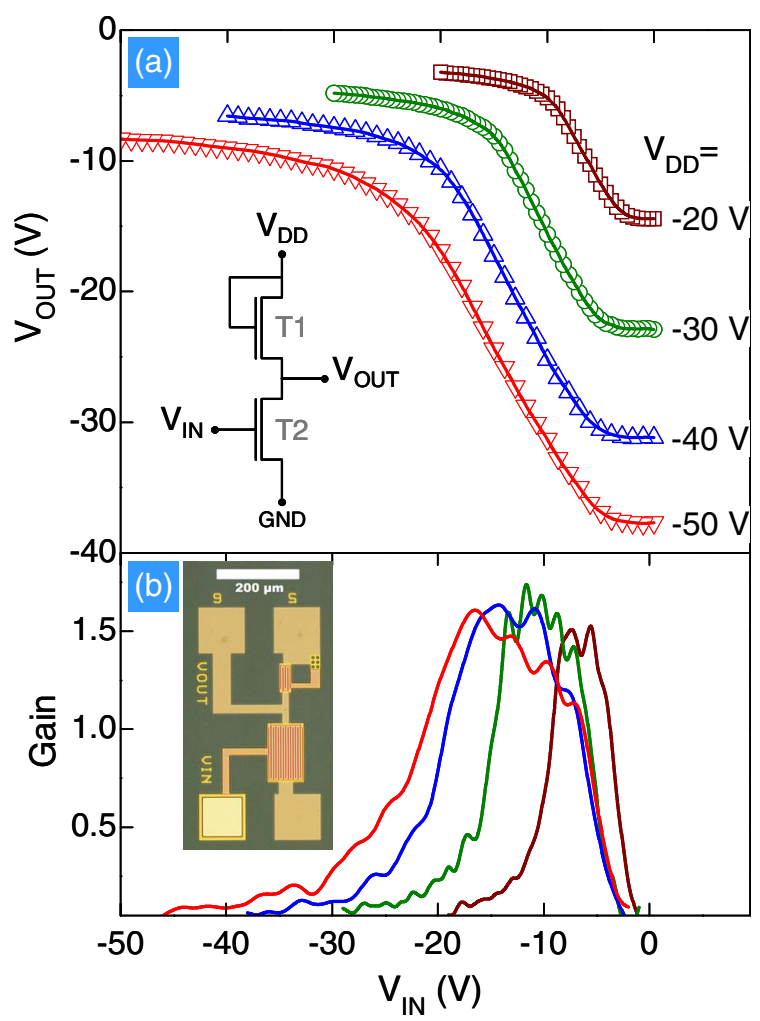

FIG. 2. (Color online) (a) Quasistatic transfer characteristics obtained from a unipolar voltage inverter comprising two diF-TESADT:PTAA transistors. The inset shows the ratio-logic inverter circuitry employed. (b) Signal gain as a function of $V_{\text {in }}$ measured at different voltages. The inset shows the microphotograph of the voltage inverter. 

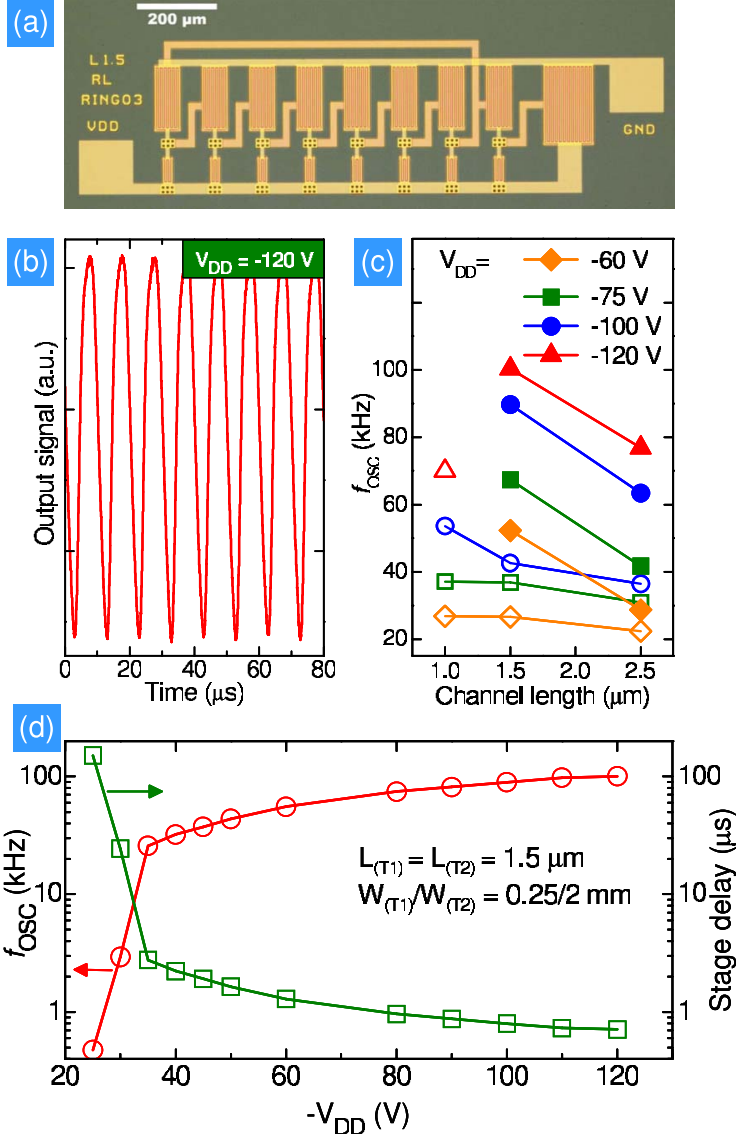

FIG. 3. (Color online) (a) Microphotograph of a representative unipolar seven-stage ring oscillator circuit fabricated in this work. (b) Output signal of a ring oscillator measured at a supply voltage of -120 V. (c) Oscillation frequency $\left(f_{\text {osc }}\right)$ as a function of design rule (i.e., $\left.L\right)$ and supply voltage measured before (open symbols) and after (solid symbols) thermal annealing in high vacuum. (d) Dependence of $f_{\text {osc }}$ and the corresponding stage delay on $V_{\mathrm{DD}}$ measured for a seven-stage ring oscillator with $L_{(\mathrm{T} 1)}=L_{(\mathrm{T} 2)}$ $=1.5 \mu \mathrm{m}$ and $W_{(\mathrm{T} 1)} / W_{(\mathrm{T} 2)}=0.25 / 2 \mathrm{~mm}$.

based OFETs is very important particularly for integration into multitransistor circuits.

Based on the diF-TESADT:PTAA blend a number of integrated circuits starting with a simple voltage inverter were fabricated. The inset in Fig. 2(a) shows the schematic of the diode-connected load inverter employed. ${ }^{9}$ Transistor widths used here were $W_{(\mathrm{T} 1)} / W_{(\mathrm{T} 2)}=1 / 8$. Good transfer characteristics [Fig. 2(a)] with signal gain of $\left(\partial V_{\text {out }} / \partial V_{\text {in }}\right)>1.5$ [Fig. 2(b)] are achieved over a range of supply voltages, thus making the inverter suitable for application in more complex circuits.

To demonstrate this we have built several multistage ring oscillators [Fig. 3(a)] employing different design rules. A representative example of the output signal of a seven-stage ring oscillator is shown in Fig. 3(b). In this circuit the oscillation frequency $\left(f_{\text {osc }}\right)$ is inversely proportional to the delay from one inverter stage. This delay is in turn determined by the current charging or discharging the output node of the inverter $\left(V_{\text {out }}\right)$ by the capacitance at this node and by the voltage that must be reached to propagate the oscillation to the next stage. The larger the currents and the smaller the output capacitance, the shorter will be the time needed to pull up or down each output node, and the faster the oscillation frequency. Pull-up and pull-down delays will also be slightly different, making an exact analysis of the oscillation frequency rather cumbersome. In any case one expects that a higher $V_{\mathrm{DD}}$ will result in higher transistor overdrive $\left(V_{\mathrm{G}}-V_{T}\right)$, larger charging currents, and thus higher $f_{\text {osc }}$. A smaller $L$ means higher charging currents and lower capacitance at the output nodes, also resulting in a higher oscillation frequency. The dependence of the oscillation frequency on the design rule [i.e., the channel length $(L)$ of the transistors comprising the inverters] before (open symbols) and after (solid symbols) annealing, is shown in Fig. 3(c). As can be seen, $f_{\text {osc }}$ increases with decreasing $L$ especially at high supply voltages $\left(V_{\mathrm{DD}}\right)$. By annealing the circuits in vacuo, $f_{\text {osc }}$ increases further and reaches a maximum value of $100.2 \mathrm{kHz}$, which corresponds to a stage delay of $712 \pm 9 \mathrm{~ns}$ measured at $V_{\mathrm{DD}}=-120 \mathrm{~V}$ [Fig. 3(d), with the dependence of $f_{\text {osc }}$ on $V_{\mathrm{DD}}$ also shown].

In summary, we have demonstrated the use of highmobility, solution-processable polymer-small molecule semiconductor blends for the fabrication of organic transistors and integrated circuits. Inverters and multistage ring oscillators with a single stage delay down to 712 ns have been realized. This level of performance qualifies polymer-small molecule blends as serious candidates for use in future organic electronics applications.

The authors are grateful to the Engineering and Physical Sciences Research Council (EPSRC) and Research Councils U.K. (RCUK) for financial support. T.D.A. is an EPSRC Advanced Fellow and a RCUK Fellow/Lecturer.

${ }^{1}$ G. H. Gelinck, H. E. A. Huitema, E. van Veenendaal, E. Cantatore, L. Schrijnemakers, J. B. P. H. van der Putten, T. C. T. Geuns, M. Beenhakkers, J. B. Giesbers, B.-H. Huisman, E. J. Meijer, E. M. Benito, F. J. Touwslager, A. W. Marsman, B. J. E. van Rens, and D. M. de Leeuw, Nature Mater. 3, 106 (2004)

${ }^{2}$ S. Steudel, S. De Vusser, K. Myny, M. Lenes, J. Genoe, and P. Heremans, J. Appl. Phys. 99, 114519 (2006).

${ }^{3}$ F. Eder, H. Klauk, M. Halik, U. Zschieschang, G. Schmid, and C. Dehm, Appl. Phys. Lett. 84, 2673 (2004).

${ }^{4}$ T. W. Kelley, P. F. Baude, C. Gerlach, D. E. Ender, D. Muyres, M. A. Haase, D. E. Vogel, and S. D. Theiss, Chem. Mater. 16, 4413 (2004).

${ }^{5}$ T. D. Anthopoulos, B. Singh, N. Marjanovic, N. S. Sariciftci, A. M. Ramil, H. Sitter, M. Colle, and D. M. de Leeuw, Appl. Phys. Lett. 89, 213504 (2006).

${ }^{6}$ H. Sirringhaus, Adv. Mater. (Weinheim, Ger.) 17, 2411 (2005).

${ }^{7}$ S. H. Ko, H. Pan, C. P. Grigoropoulos, C. K. Luscombe, J. M. J. Frechet, and D. Poulikakos, Nanotechnology 18, 345202 (2007).

${ }^{8}$ W. Fix, A. Ullmann, J. Ficker, and W. Clemens, Appl. Phys. Lett. 81, 1735 (2002).

${ }^{9}$ T. D. Anthopoulos, D. M. de Leeuw, E. Cantatore, P. van 't Hof, J. Alma, and J. C. Hummelen, J. Appl. Phys. 98, 054503 (2005).

${ }^{10}$ A. Babel, J. D. Wind, and S. A. Jenekhe, Adv. Funct. Mater. 14, 891 (2004)

${ }^{11}$ M.-B. Madec, D. Crouch, G. R. Llorente, T. J. Whittle, M. Geogheganc, and S. G. Yeates, J. Mater. Chem. 18, 3230 (2008).

${ }^{12}$ T. Ohe, M. Kuribayashi, R. Yasuda, A. Tsuboi, K. Nomoto, K. Satori, M. Itabashi, and J. Kasahara, Appl. Phys. Lett. 93, 053303 (2008).

${ }^{13}$ R. Hamilton, J. Smith, S. Ogier, M. Heeney, J. E. Anthony, I. McCulloch, D. D. C. Bradley, J. Veres, and T. D. Anthopoulos, Adv. Mater. (Weinheim, Ger.) (to be published).

${ }^{14}$ S. K. Park, D. A. Mourey, I. Kim, D. Zhao, S. Subramanian, J. E. Anthony, and T. N. Jackson, Proceedings of the IEEE Electron Devices Meeting (IEEE International, New York, 2007), pp. 225-228.

${ }^{15}$ S. Subramanian, S. K. Park, S. R. Parkin, V. Podzorov, T. N. Jackson, and J. E. Anthony, J. Am. Chem. Soc. 130, 2706 (2008).

${ }^{16}$ D. J. Gundlach, J. E. Royer, S. K. Park, S. Subramanian, O. D. Jurchescu, B. H. Hamadani, A. J. Moad, R. J. Kline, L. C. Teague, O. Kirillov, C. A. Richter, J. G. Kushmerik, L. J. Richter, S. R. Parkin, T. N. Jackson, and J. E. Anthony, Nature Mater. 7, 216 (2008). 